Article

\title{
Transforming Worker-Client Identities: From Shelters to Housing First
}

\author{
Cecilia Hansen Löfstrand ${ }^{1, *}$ and Kirsi Juhila ${ }^{2}$ \\ ${ }^{1}$ Department of Sociology and Work Science, University of Gothenburg, Sweden, E-Mail: cecilia.lofstrand@gu.se \\ 2 Faculty of Social Sciences, Tampere University, Finland; E-Mail: kirsi.juhila@tuni.fi \\ * Corresponding author
}

Submitted: 16 March 2021 | Accepted: 19 May 2021 | Published: 26 August 2021

\begin{abstract}
The Housing First (HF) approach to counteracting homelessness, stemming from the USA, is advocated as a blueprint for homelessness policy change in Europe, including the Nordic countries. In contrast to traditional homelessness policies based on shelters as the first step towards ending homelessness, the HF policy discourse regards access to one's own housing as a basic human right that should not be conditional upon good or acceptable behaviour. Building on ethnographic research in a Swedish HF unit striving to implement the HF approach 'by the book,' which includes both focus group interviews with workers and observations of worker-client interactions during home visits, we show how the new HF policy challenges both workers and clients, who used to encounter each other in shelters but now meet in clients' own homes, transforming their identities. We demonstrate how workers account for transformations in worker-client identities by referring to how they and their clients used to think, talk and act, thus contrasting their new identities with their former selves. Moreover, in their efforts to accomplish their actual work tasks within the framework of the new HF policy discourse in the homes of formerly homeless clients, we show how workers struggle with their identities when they encounter clients in practice. In their accounts of policy change, the workers embraced their new identities with pleasure, but in practice, they were hesitant when dealing with issues of concern, such as their clients' use of tobacco, alcohol and drugs. In sum, it becomes complicated in practice.
\end{abstract}

\section{Keywords}

homelessness; Housing First; worker-client identities; discursive change; practice

Issue

This article is part of the issue "Home- and Community-Based Work at the Margins of Welfare: Balancing between Disciplinary, Participatory and Caring Approaches" edited by Kirsi Juhila (Tampere University, Finland), Cecilia Hansen Löfstrand (University of Gothenburg, Sweden) and Johanna Ranta (Tampere University, Finland).

(C) 2021 by the authors; licensee Cogitatio (Lisbon, Portugal). This article is licensed under a Creative Commons Attribution 4.0 International License (CC BY).

\section{Introduction}

The Housing First (HF) approach to counteracting homelessness, stemming from the USA (Tsemberis, 2010; Tsemberis \& Eisenberg, 2000), is advocated as a blueprint for change in homelessness policies in Europe, including the Nordic countries (Hansen Löfstrand \& Juhila, 2017). In European research based on data from different countries, the HF approach has been portrayed as a successful response to homelessness and can be seen to constitute a moral story of why policy change-from shelters to HF-is needed (Hansen Löfstrand \& Juhila, 2017).
Arguably, accounts of policy change (on what it entails and why it is needed) becomes an institutionalised discourse in country and policy contexts as well as concrete social settings (cf. Miller, 1994). The HF policy discourse claims ownership of highly respected values and principles in the welfare state that are easy to agree with and hard to resist, such as emphasising the right to housing, seeing clients as capable of making their own choices, and respecting the wishes and wants of clients to be heard and acted upon. A key to understanding accounts of the policy change from shelters to $\mathrm{HF}$ and the efforts made to achieve the change in 
practice is by recurrently drawing upon 'contrasting comparisons' (Hansen Löfstrand \& Juhila, 2017, pp. 24-27; Smith, 1978) between the 'old' shelter system and the 'new' HF approach.

The set of fundamental assumptions that the HF policy discourse is based on is contrasted with earlier homelessness policies based on 'rehabilitation first' ideas, which regard shelters as the first step in 'curing' homelessness and one's own apartment as a result of the rehabilitation process. Quite the opposite, in the HF policy discourse, access to housing is defined as a basic human right that should not be earned or be conditional upon good or acceptable behaviour. Access to ordinary housing is seen as the starting point (rather than an endpoint) for the subjective change the client is proclaimed to need; thus, according to the HF policy discourse, homeless clients should promptly get access to their own home, i.e., an apartment with tenant's rights. Furthermore, housing and treatment must be offered separately; access to housing should not depend on a client's acceptance of treatment. Additional basic principles are consumer choice and self-determination, meaning that clients are regarded as competent choice makers, who should be given the opportunity to make their own decisions. Active and engaged professional support work should be offered without coercion and should be based on each individual client's own strengths, needs and goals. It should also be directed towards recovery, based on the principle of harm reduction. In practice, this means that staff should not, for example, demand total abstinence from alcohol and other substances, and clients should be able to decline offers of treatments without risking their access to housing and without being treated adversely by staff. Lastly, professional support work should be provided flexibly, depending on a client's needs and wants, and as long as the client desires (Pleace, 2018; Tsemberis, 2010).

In Sweden, the introduction of the HF approach was research-driven, introduced by Lund University in 2009 (Knutagård \& Kristiansen, 2013, p. 94), when the first national conference promoting the HF approach took place. Interest in the HF approach was very high, and two Swedish municipalities immediately decided to initiate HF services (Knutagård \& Kristiansen, 2013, p. 95). Since then, many more Swedish municipalities have striven to implement and run small-scale HF services.

Based on a mobile ethnography of work in one Swedish HF unit, including focus group interviews with workers and observations of worker-client interactions during home visits to clients, we aim to show how the 'new' HF policy challenges workers and clients to transform their identities. We ask how workers account for policy change, and how they struggle with their identities when they encounter clients in practice during the home visits.

The HF policy discourse consists of fundamental assumptions and vocabularies of setting members (Miller, 1994, p. 283). However, it can also be observed in interactions between staff and clients, although such interactions are always creatively achieved in relation to the particularities of each situation (Miller, 1994, p. 283). We analyse whether and, if so, how workers in the HF setting draw on the HF policy discourse as a resource to understand and assign meaning to their work, themselves as workers and their clients, and we interpret their 'talk about work' as accounts of transformations in worker-client identities. In addition, we analyse workers' practical efforts to accomplish their actual work tasks during home visits to formerly homeless clients. It is important to study the home visit as it is seen as key to the HF approach (Tsemberis, 2010). The policy change implies that the workers and clients, both of whom have experienced the 'old' homeless shelter environment, now need to adjust to interacting in the clients' homes. The home thus becomes a place for professional care and support work.

Whereas international HF research on policy and national levels is abundant, research on the implementations of HF policies at the grassroots level and the challenges it involves is scarce and called for (Raitakari \& Juhila, 2015). Our contribution is precisely such a frontline perspective of what the policy change from shelters to HF entails in terms of transformations of workerclient identities. We show from the workers' perspectives how they need to create a new way of doing work under the HF policy approach to ending homelessness. To achieve our objective, a detailed ethnographic study - to study both talk about work and actual work practices-was required.

In the following, we first account for our study design, methods, materials and the analytic concepts that we draw on to make sense of our empirical materials. We then present our core findings of the detailed data analysis in two separate sections (3.1 and 3.2) and conclude with a brief discussion.

\section{Method}

\subsection{Setting and Data}

As mentioned, many Swedish municipalities currently run small-scale HF services. The setting sampled and studied to show how the 'new' HF policy challenges workers and clients to transform their identities is referred to throughout this article as the HF unit and it is located in the southern part of Sweden. The HF unit represents a service that has made a conscious effort to implement the HF policy 'by the book' or according to Tsemberis' (2010) Housing First: The Pathways Model to End Homelessness for People with Mental Illness and Addiction (or The Housing First Manual, as it is referred to by the staff in the unit). This makes it a particularly interesting case. For quite some time the 'pathways HF' approach has been internationally promoted and depicted as "the original and truest way to implement HF" (Raitakari \& Juhila, 2015, p. 146) and has 
been adopted across the USA and in Europe, including the Nordic countries. Yet, detailed ethnographic studies of its implementation and the challenges and struggles involved in transforming worker-client identities in concrete local settings are scarce-close to non-existent.

The staff in the HF unit sampled for our study are social workers and support workers, most of whom have extensive experience working in the old shelter system. The HF unit has 12 workers divided into two teams to conduct home visits in the homes of approximately 60 clients. The clients have previously experienced lengthy periods of homelessness, shelter living and institutional treatment, and many have substance abuse and mental health problems.

For our purpose of scrutinising how the 'new' HF policy challenges workers and clients to transform their identities, we draw on a combination of empirical materials unique to the field of HF research. The first dataset was derived from two focus group interviews with workers at the unit conducted in early 2018. These interviews provided a forum for collegial discussions as joint talk among staff, whereby workers assigned meaning to their work and to themselves as workers as well as their clients. We interpret their joint talk about work in the HF unit as accounts of transformations in worker-client identities. We coded the interview data by including all talk on changes in worker-client identities and, more specifically, all instances in the interview transcripts where workers provided contrasting comparisons of 'old' and 'new' ways of accomplishing work. The interview extracts were then analysed jointly by the authors, who agreed to select two examples for this article to illustrate typical accounts of transformations in worker-client identities in an $\mathrm{HF}$ unit.

The second dataset was derived using the mobile ethnographic approach of shadowing (Czarniawska, 2007). In April-October 2018, we accompanied workers at the HF unit during 16 home visits, and the data were recorded by keeping a detailed research diary including fully developed field notes. Shadowing enabled us to observe actual worker-client interactions during home visits and, hence, produced data on workers' efforts to accomplish their work within the framework of the new HF policy discourse and in the homes of clients. For the purposes of this article, we coded all instances in the field notes where workers somehow struggled to accomplish their work and their new identities in relation to their clients, and we found that work tasks and interactions revolving around clients' use of alcohol or drugs were particularly challenging for the workers. The field notes also include data on staff talking about and reflecting on how they think they should accomplish work tasks in accordance with the HF method. All the coded extracts from the field notes were analysed jointly by the authors, who also agreed on which three extracts to draw on to illustrate the challenges involved in transforming worker-client identities and the approaches used to accomplish this in the practical work in an HF unit.

\subsection{Analysing Worker-Client Identity Change}

As theoretical tools for our analysis, we draw on the concepts of contrasting comparisons, identity categorisations and relational pairs. We apply the concept of 'contrasting comparisons' (Hansen Löfstrand \& Juhila, 2017, pp. 24-27; Smith, 1978) as a tool to analyse "how setting members move from one institutional discourse to another" (Miller, 1994, p. 297) in accounts of workerclient identities and worker-client interactions during home visits. As an institutional discourse, the HF policy discourse shapes what can be said in the social setting studied (Miller, 1994, p. 286).

In studying contrasting comparisons, we pay special attention to 'old' and 'new' worker and client identities. We regard both worker and client identities as constructed in talk and text in social settings; hence, we draw on the work developed in discursive psychology (Antaki \& Widdicombe, 1998a; Benwell \& Stokoe, 2006; Edwards et al., 1992; Wiggins \& Potter, 2008) and membership categorisation analysis (Hester \& Eglin, 1997; Housley \& Fitzgerald, 2002; Sacks, 1972/1990, 1992). More specifically, we draw on the concept of 'identity categorisation' in our analysis. By the concept of identity categorisation, we emphasise that identity is relational. Thus, workers construct their identities in relation to their clients, and by analysing interview talk and home visit interactions, we can understand how identities are produced (Benwell \& Stokoe, 2006, p. 6). As pointed out by Antaki and Widdicombe (1998b, p. 3), producing or constructing identities involves "speaking, being spoken to, or being spoken about" and to "have an identity" means being casted "into a category with associated characteristics or features." These characteristics often have a moral dimension, especially when identity categories expressly imply rights and responsibilities (Jayyusi, 1991, p. 241). Based on these definitions of identity, the data of this study-focus group interviews with the HF unit staff members and field notes on their home visits-are seen as arenas of spoken interactions, where worker-client identity categorisations with certain characteristics and features are produced.

As mentioned, identity categorisation concerning oneself is accomplished in relation to other people. These others can either be present or absent in the interaction. The relational nature of categorisation is significant to analyse in both of our data types. In talking about their work, the HF unit workers categorise themselves in relation to their clients (focus group interviews), and in interacting with each other during the course of home visit interactions, workers and clients produce their specific roles in relation to each other (field notes). This is where the concept of 'standardised relational pairs,' originating in Sacks' (1972) influential work, becomes important. When two identity categories are paired together-as worker-client identities - their characteristics, features, rights and responsibilities are reciprocal (Psathas, 1999, p. 143) and interdependent, meaning that one identity category, e.g., the worker, cannot 
exist without the other, e.g., the client, and vice versa. As Mäkitalo (2014, p. 26) puts it: "If one is mentioned, the other is simultaneously made relevant without mentioning." The HF worker-client combination is clearly this kind of a relational identity pair.

Identity categorisations are contextually embedded activities. The obvious local contexts for identity categorisations in this study are joint collegial talk (in focus group interviews) and worker-client interactions during home visits. The workers concurrently produce and orient to a certain context for their talk, namely their 'old' work in shelters and their current 'new' work in the HF unit. However, we do not regard context as an external determinant for identity categorisation in the 'here and now' interactions and talk (Juhila \& Abrams, 2011, pp. 280-283; cf. Miller, 1994, p. 283). Instead, as pointed out by Silverman (2000, p. 66), we assume that the workers themselves "actively produce a context for what they do," and because of this, we as researchers need to investigate "the ways in which people themselves categorise to make sense of people, events and actions in their local context" (Hester \& Eglin, 1997, as cited in Mäkitalo, 2014, p. 26). As will be shown, workers' talk on 'old' work and the accompanying identities created a point of reference for accounts of 'new' work identities and, simultaneously, for their standardised relational pairs, 'old' and 'new' client identities.

By comparing and even contrasting 'old' and 'new' identity categories, moral judgements on which one is better and on what grounds are produced. In analysing the interview talk, we focus especially on comparing and contrasting, which is often done by presenting voices and reported speech both from the past and the present, including accounts of how they differ from each other (on voices and reported speech as interactional devices see Holt \& Clift, 2007; Juhila et al., 2014). In home visit interactions, 'old' and 'new' work is not talked into being in the same way as in the interviews. However, in analysing contrasts between 'old' and 'new' in the field notes, we pay special attention to how workers struggle to accomplish the HF policy and their ' $n e w$ ' identities in frontline encounters with clients.

\section{Findings}

Our first finding on the interview data was the dominance of the HF policy discourse in the workers' accounts, whereas talk about the traditional and mainstream shelter system was oriented towards being unwanted and inappropriate. At the same time, the staff occasionally struggled to carry out their work in accordance with their 'new' worker identities as was evident from our observations of home visits.

\subsection{Producing New Worker-Client Identities in Focus Group Interviews}

As stated above, the repeated theme in the focus group interviews is the description of the change in work in the
HF unit, compared to the shelter context. In the following, we analyse in detail two examples from the interviews to demonstrate how the workers produce the contrast between 'old' and 'new' worker-client identities. Example 1 illustrates how workers orient to their work now and how it differs in relation to their prior way of working:

1. M1: Our mission is, well, it is that they can remain in their housing, that they will succeed in handling this, yes, to live in the apartment quite simply. And then to come there and see that 'oh, it's filled with stuff from floor to ceiling and it's a sanitary nuisance'; well, then you know that the only thing to do is to fish for a change [laughter]. I think it is very good. And our method takes as its point of departure the wishes of the client, and it's a bit... because I come from an emergency shelter, where we used to have keys to go into their rooms and one hardly knocked on the door before entering the rooms. Here, we often have keys, but it's because the client wishes that we should have keys, and we do not enter with keys. I've never experienced that during my time here. I've been here a little less than a year. We knock on the door; it's up to them if they choose to open the door. It's like this: 'May we come in?' We take off our shoes and we are in their home. There's a totally different power balance.

2. F1: Yes, it is.

3. M1: So, I think the power balance is totally different, and it makes it possible for us to learn what it is that the client wants and what we, what it is that they want to do really.

4. F2: And there is no exercise of public authority.

5. M1: No.

6. F2: I think you feel that it's almost as if you become friends.

7. M1: Yes, it's very different, yes. The same clients who I have met in the shelter system that I now meet here, they are much more open. Precisely, that they talk honestly about how they live, about the criminality, about drugs and so on.

8. K2: And it's nice not to have to be condemnatory, to have that function, 'oh, now I must report this.' You don't have to do that, and that's so nice.

9. M1: Yes, it really is.

M1 talks on behalf of the whole work team in the HF unit by using pronouns "our" and "we" (turn 1). Formulations, such as "our mission" and "our method," can be interpreted as referring to The Housing First Manual and its committed implementation in the unit. The worker identity in the HF context is connected in this example to such characteristics as helping clients remain in their housing, fishing for a change, taking the wishes of the client as a starting point, letting the client choose to open the door, always knocking before entering clients' homes (turn 1) 
and learning what clients want (turn 3). These characteristics are strengthened by comparing them to the 'old' emergency shelter system with an opposite worker identity, comprising such activities as hardly knocking when entering clients' rooms (turn 1), exercising public authority (turn 4 ) and being condemnatory (turn 8 ).

The difference between 'old' and 'new' identities is intensified with extreme case formulations (Pomerantz, 1986): "I've never experienced," "totally different" and "very different" (turns 1, 3 and 7). Furthermore, reported speech is used in emphasising the split between 'old' and 'new' ways of working. The 'new' worker asks clients they may come in into their home, signalling an equal relationship, whereas the 'old' one responds to the client's doings by saying "oh, now I must report this," signalling a hierarchical relationship. The workers are very likeminded in their talk. They confirm each other's views with short supporting responses (turns 2, 5 and 9), and smoothly complement each other's turns of talk (turns 4, 7 and 8). They also remember the 'old' times in a unanimous way. A moral dimension is clearly present in the categorisation: Past, 'bad' shelter-related practices have been substituted with 'good' HF practices.

As usual in category constructing processes, the workers do their own identity categorisation in relation to other people, and in this case, especially to clients' identities. As counterparts of the 'new' professional identities, 'new' clients-different from the old ones-are thus described as having and presenting wants and wishes, being open and talking honestly, and even becoming the workers' friends (turns 1, 3, 6 and 7). However, sometimes clients' identities become stuck in the 'old' homelessness policy discourse (example 2):

1. F1: It's been a lot of work with many [clients]. We have gone there, we have been standing outside, nobody is home or they are at home, we know that, but they do not open the door, they do not want us there.

2. F2: So, we leave notes and send text messages.

3. F1: Yes, we try. And then, little by little, after a lot of patience. It's insane really. Without hunting them down, instead, they should be reassured that this is of concern. We are not here to control or hunt, and all the time, we try to separate the state of the apartment; even if we do support them and can give advice as regards to how it [the apartment] should look when it's not okay, we don't have anything to do with it. We will not evict them.

4. F2: We are very clear when we leave notes for them [saying] that 'we only want to know if you're okay, how you are,' and...

5. F1: Yes, 'the housing organisation has been here and please just let us know that you're okay.'

6. F2: Yes, there are no demands.

7. F1: You get worried and we can leave a note in the end [saying] that if [they] do not get in touch within a week or three days, we will use a key to enter....
But then they think it is annoying and get in touch [with us], like, they send a text message, or they are at home on the next occasion.

8. F1: We do not scold them or say 'you have not been at home for three home visits, where have you been?' It's nothing like that, and I think it's taken some time for them to get used to that, that it doesn't work like that. Because they are used to that from staying in emergency shelters, where the staff say 'you shall put that thing there, you cannot enter like that, and you know that...'

9. F2: 'You have to show me what you have in your bag before I can let you inside,' and 'yuck, you cannot smoke in your room.' It's disciplining.

10. F1: It feels so good to not have to do that.

11. F2: Yes.

12. M1: Yes, indeed. That's the best thing, I think.

13. F1: Yes, you get to be the good one all of a sudden [laughter].

14. F2: For once.

As in the previous example, the workers talk of "we" creates the sense of a shared worker identity with certain characteristics. The shared way of working is not, however, always in balance with the clients' expectations. Although the workers try to visit the clients' homes with caring intentions, only wanting to know that they are fine, the clients are suspicious and do not always open their doors (turns 1-5). This discrepancy between the workers' and the clients' identity categories (good intentions vs. suspicion) is accounted by presenting that the clients still define the workers and their characteristics according to the 'old' shelter system, when they were still demanding, scolding, domineering, disciplining, controlling, hunting and had the power to evict (turns 3,8 and 9).

Again, the 'old' shelter discourse and the 'new' HF discourse and their contrasting comparisons are very clearly talked into being. In doing this, conversational remembering by using reported speech plays a big role. For example, the 'old' shelter worker might have said that "you have to show me what you have in your bag before I can let you inside" or "yuck, you cannot smoke in your room" (turns 8 and 9). Whereas the 'new' worker can, for example, write a note to the client who does not open the door that "we only want to know if you're okay, how you are" (turn 4).

All in all, the message seems to be that the clients do not leave their 'old' identities as people subjected to control to create new 'HF client identities,' i.e., those who are cared for by workers and who have the right to make their own choices. Clients do not leave their 'old' identities if they do not trust that the workers have really changed their ways of working and abandoned their 'old' shelter identities. Thus, overcoming the discrepancy between the current workers' and clients' identities takes a lot of time and assuring work conducted by the workers. 


\subsection{Struggling between 'Old' and 'New' Policies in Worker-Client Interactions during Home Visits}

As has been shown, the HF policy discourse dominates the workers' accounts in the interviews, and the 'old' shelter system as well as the workers' 'old' identities are talked about as unwanted and inappropriate. In analysing the contrasts between 'old' and 'new' in the field notes, based on observations during the workers' home visits to clients, we focus on how workers struggle to accomplish the HF policy and their 'new' identities in encounters with clients in or near their homes. We find that in these frontline encounters, they do struggle to carry out the home visit work in a way that agrees with their 'new' worker identities and the HF policy discourse talked into being during the interviews.

According to the HF policy discourse, the main mission of the worker in an HF unit is to see to it that clients can remain in their housing or, in other words, succeed in living in the apartment. In the following, we draw on three examples to illustrate the workers' efforts to accomplish home visits while simultaneously managing issues of concern: Clients' use of cigarettes, drugs and alcohol. In the 'old' shelter system, clients' use of alcohol or illicit drugs, if detected, would have led to disciplinary measures, such as reprimands, reports and even eviction as the ultimate sanction. How to manage clients' use of tobacco, alcohol and drugs, particularly during home visits, constitutes a practical challenge for support workers, since according to the HF policy discourse, all clients should be regarded as competent choice makers and are, thus, capable of making their own decisions about, for example, the use of cigarettes, alcohol and substances. Furthermore, according to the same policy, support work should be offered without coercion, based on individual clients' own needs and goals, oriented towards recovery and based on the principle of harm reduction. Therefore, workers should not demand abstinence from alcohol and other substances (Pleace, 2018; Tsemberis, 2010). At the same time, the workers are aware of the power of the property owner, who may ultimately resort to the means of eviction if the clients do not follow the rules of a normal tenancy. The workers, therefore, need to find new ways of managing their clients' use of cigarettes, alcohol and drugs. However, as illustrated below, this challenge may be approached in different ways.

In our first example, Maria and Martin (two support workers) visit the home of Timmy (a male client), who lives in one of the HF unit's apartments. Like all clients of the HF unit, Timmy has a second-hand lease of the apartment, but he will receive a first-hand lease after 18 months if no serious breaches have reached the property owner. Timmy asks the support workers if it is okay for him to smoke a cigarette during the home visit, which causes concern; how to respond to the request constitutes a challenge for the support workers in their efforts to adapt to the 'new' policy (example 1):
Timmy asks if it is okay for him to smoke. "If you can desist, it would be good. But it is your apartment and your choice," says Maria. Timmy reaches for a box where he stores tobacco and paper, and rolls a cigarette. "Have they told you that smoking is something they can comment on when getting a first-hand lease?" Maria asks. "No," Timmy says; he has not heard about this. "No, God, now I scared you," says Maria, who continues to explain that the property office may have to clean the apartment if it smells too much of smoke. Timmy replies that he mostly smokes on the balcony and that smoking is not forbidden.

In this example, the worker begins by asking the client to desist and makes the point that whether or not Timmy chooses to do so is his choice, in accordance with the 'new' HF policy discourse. The worker then starts explaining why heavy smoking in the apartment may become a problem for the client. The property owner might object if they need to clean the apartment and smoking heavily might hinder Timmy's chances of getting a firsthand lease. She then interrupts herself and expresses great concern about what she has just said, thinking she might have scared him. This way of putting pressure on Timmy to think again regarding his decision to smoke in his home is similar to the coercive measures of the 'old' policy and, thus, also echoes the 'old' worker identity category. Timmy, however, concludes that smoking cigarettes is not forbidden, according to the rental policy or by other means:

Once outside the house after the home visit at Timmy's, Martin says it feels like he has swallowed an ashtray. Maria agrees and explains to me [researcher] that their management has given them directives to say 'no' to clients who ask if they can smoke during a home visit. "But it's a little difficult. It is the client's home, but it is our work environment, too, and you have to find some way to balance that. We are not a controlling business," says Maria.

Aside from the harm-reduction perspective, the support workers are also concerned about their own work environment-the clients' homes. Their management's advice - to decline requests from clients' about smoking during the home visit-is difficult to accomplish within the framework of the 'new' HF policy discourse, whereby workers are no longer "in the controlling business," as expressed by Maria. The example thus illustrates that while the client seems to have adjusted to the new 'free' identity of clients in the HF unit, the workers struggle with adjusting to the principle of letting clients make their own choices.

In another example, support worker Steve visits the home of client Jenny to accompany her to the hairdresser. When invited into Jenny's apartment, her intake of alcohol (beer) during the home visit causes Steve some concern. In approaching the client with his concern, 
the support worker refers to "others" among the staff at the HF unit and their rules: "I have heard that staff in the HF unit usually try to say that it is good if the clients do not drink during the home visit." He, thereby, avoids positioning himself as the controlling worker carrying the 'old' worker identity:

We [support worker and researcher] take the elevator up to Jenny's apartment and knock on the door. Jenny shouts from inside that we should come in. When we enter her apartment, Jenny sits on her bed, which consists of a spring bottom lying on the floor, full of duvets and big pillows. She has a cigarette in her mouth and drinks a $7.2 \%$ beer. In front of the bed is a coffee table. There is an ashtray and various semi-drunk glasses with juice and water, a decanter with juice, and a plate with some old meatballs. Steve enters the single room from the hallway and sits down in the only armchair. Jenny tells Steve about some friends who are "totally fucked up." She proceeds with a rather long monologue and Steve calmly answers something in the style of "no, it doesn't sound good." When Jenny goes silent, Steve says that he has heard that staff in the HF unit usually try to say that it is good if the clients do not drink during the home visit. Jenny looks sceptically at Steve. "But who's going to stop me?" she says, taking another sip of the beer. Then Steve asks her if [they] should go to the hairdresser now. Jenny gets ready by taking a few sips of beer, and then walks away with the beer can, saying she is going to put it in the fridge. Steve goes to the hallway and Jenny, too. We all leave the apartment.

Interestingly, Jenny expressly resists Steve's implicit request not to drink alcohol during the home visit, and by stating "who's going to stop me," Jenny shows she has adjusted to the 'new' HF policy discourse and identity, according to which workers should not demand or coerce clients into anything. In our third example, support worker Caroline visits Robin, and during their small talk outside afterwards, it becomes evident that Robin buys and uses prescription drugs in illegal ways (without a prescription from a medical doctor and bought on the 'black market'). In this final example, the roles are almost reversed: The client expresses concern and justifies his choices and actions, whereas the worker's attitude is non-judgmental, even supportive:

Robin (client) and Caroline (support worker) are standing outside Robin's apartment making small talk. Robin does not seem to be in a hurry and seems to enjoy talking to Caroline. He has exercised a lot, he says. Caroline and Robin talk a little about how hot it has been the last few weeks. Meanwhile, Robin's phone rings and he answers. He happens (or is it intentional) to put on the speakerphone, so we can all hear what the person phoning Robin is saying. It is a man's voice asking if Robin wants to buy Stesolid (prescription drug) as they discussed earlier. They agree on a time to meet up. The man's voice also asks if Robin wants to buy Ritalin (another type of prescription drug), but Robin says he already has it. They hang up. Robin explains to Caroline that he needs the Stesolid "in order to go out." He could drink (alcohol) instead, but he does not like drinking. Robin says he has been to a doctor to talk about his anxiety and social phobia, but the doctor did not want to prescribe Stesolid. Thus, he buys it on the black market instead. It is like Robin wants to apologise a little, but Caroline is very non-judgmental. She just says that it is good that he finds strategies to be able to leave the house.

Taken together, the examples illustrate that what is at stake regarding the use of tobacco, alcohol and drugs among the clients at the HF unit is the workers' (and clients') struggles between 'old' and 'new' policies and identities. How to express and display concerns in accordance with the HF policy discourse constitutes a very practical challenge for the workers. Furthermore, we have shown how the implementation of the 'new' HF policy depends on the frontline support workers' practical accomplishments in interactions with their clients, i.e., their interactional competence. Finally, as illustrated, the workers do not only need to relate to each unique client and their wishes, but also-more or less implicitly-to the property owner, who they know has the ultimate power to decide if the clients can or cannot keep their apartments. This puts the workers in a tricky position, balancing between material realities and conditions on the housing market on the one hand, and the challenge to live up to the HF policy discourse in reality on the other.

\section{Concluding Discussion}

Our objective was to show how the policy change from shelters to HF challenges workers and clients, who have previous experiences with the homeless shelter system, to transform their identities. The specific HF setting sampled and studied to show how the 'new' HF policy challenges identities is a particularly interesting case, since the unit's goal was to implement the new HF policy 'by the book,' according to the manual presenting the 'pathways HF' model (Tsemberis, 2010). As mentioned, this approach has been widely recognised as "the original and truest way to implement HF" (Raitakari \& Juhila, 2015, p. 146) for quite some time and has been adopted on both sides of the Atlantic. Yet, detailed ethnographic studies of the challenges and struggles involved in transforming worker-client identities towards 'new' ways of working are close to non-existent. Our study hence constitutes an important contribution to the HF research literature. Our study also contributes useful knowledge when planning to implement policy changes targeted at 
marginalised individuals, when replacing coercive and disciplining approaches with inclusion and participation, and when designing HF studies. Our study points out the usefulness of studying what goes on at the grassroots level.

We have shown that in joint talk among colleagues within the framework of focus group interviews, workers account for their new identities in line with the HF policy discourse and express how they have embraced their new identities with pleasure, e.g., it feels good to "get to be the good one," as expressed by one of the workers. Their 'old' worker identity and the traditional shelter system are depicted as obsolete and unwanted. However, in the interviews, the workers express concerns about hesitant clients, who have not yet adapted to the 'new' HF policy with the 'new' client identities, and consequently, they do not really believe or trust the changes in worker identities that workers account for in the interviews. The worker-client is, hence, a typical relational identity pair. However, workers express concerns that they do not match but build on opposite categorisations, as the workers have adapted to a 'new' worker identity, whereas the clients are still stuck in the 'old' discourse and identity.

However, in the field notes illustrating the workers' efforts to accomplish the 'new' HF policy in practice and particularly when managing issues of concern, such as their clients' use of tobacco, alcohol and drugs in their units, we find quite the opposite conflict in the workerclient relational pair and categorisations. In practice, the workers are hesitant as regards to how to deal with these issues of concern, whereas clients seem to have adjusted to the 'new' freedom endowed on them within the framework of the HF policy discourse. Hence, the transformation from the 'old' worker identity and ways of getting things done to the 'new' worker identity and practices are easily explained and vividly accounted for by way of reported speech in the interviews, but the distinction between 'old' and 'new' identities and practices are not easily upheld in the workers' practical achievement of work tasks.

In practice, when striving to accomplish work, the workers have a dilemma that they need to manage. Under the HF policy discourse, they are obliged to attend to their clients' wishes, e.g., to use tobacco, alcohol and drugs, and by no means through coercion or threats. At the same time, they are acutely aware of the perspective of the property owner as an actor on the regular housing market, who has the power to hinder the client from signing the first-hand lease and, ultimately, evict the client. The workers struggle to avoid the latter, since their overall mission is to see to it that their clients can keep their apartments while simultaneously striving to respect their clients' choices. In this way, the workers promote clients' social inclusion or at least try to avoid the risk of social exclusion.

We have provided three similar examples of managing issues of concern related to clients' intake of tobacco, alcohol and drugs. During our mobile ethnography, the workers collectively (and individually) expressed these shared concerns, though the three examples show variations among staff when dealing with these issues. Staff cannot manage issues related to alcohol and drug use the way they did in the 'old' shelter system, i.e., through reprimands and evictions, but they have no clear instructions as to how they should deal with such dilemmas. They have to rely on interactional competencies to obtain wanted outcomes-not through coercion but by motivating and encouraging their clients to consider other (preferred) choices. Thus, the main challenge for the workers is how to accomplish work when clients are free to make their own choices. It requires interactional skills and soft power measures. The workers are to make their clients "work on themselves" to "achieve responsible autonomy" (Rose, 2000, p. 334; cf. Hansen Löfstrand \& Juhila, 2012; Juhila et al., 2017) but not through coercive means and disciplinary measures. This leaves workers with having to cajole and encourage clients who make sound choices and, in so doing, "appear to act out their most personal choices" (Miller \& Rose, 2008, p. 214). They have to become experts in interacting with clients and applying subtle means to teach or coax them into behaving in a responsible manner (Miller \& Rose, 2008). This challenge - to manage the support while controlling the balance-clearly relates to general ethical issues in social work, particularly social work with the objective of social inclusion.

\section{Acknowledgments}

The authors want to thank the workers who kindly agreed to participate in interviews, and all clients and workers who agreed to be observed during home visits. The research reported in this article was made possible by the Academy of Finland (decision number 307661) funding of the research project "Geographies of Homebased Service Interactions at the Margins of Welfare in Finland and Sweden" (GEOHOME). The authors would like to thank all colleagues in the GEOHOME-project, as well as the anonymous reviewers, for useful feedback on earlier versions of this article.

\section{Conflict of Interests}

The authors declare no conflict of interests.

\section{References}

Antaki, C., \& Widdicombe, S. (Eds.). (1998a). Identities in talk. SAGE.

Antaki, C., \& Widdicombe, S. (1998b). Identity as an achievement and as a tool. In C. Antaki \& S. Widdicombe (Eds.), Identities in talk (pp. 1-14). SAGE.

Benwell, B., \& Stokoe, E. (2006). Discourse and identity. Edinburgh University Press.

Czarniawska, B. (2007). Shadowing and other techniques 
for doing fieldwork in modern societies. Liber.

Edwards, D., Middleton, D., \& Potter, J. (1992). Toward a discursive psychology of remembering. The Psychologist, 5, 441-446.

Hansen Löfstrand, C., \& Juhila, K. (2012). The discourse of consumer choice in the pathways housing first model. European Journal of Homelessness, 6(2), 47-68.

Hansen Löfstrand, C., \& Juhila, K. (2017). Housing first as a moral tale and a travelling idea. In B. Andersson, F. Petersson, \& A. Skårner (Eds.), Den motspänstiga akademikern [The recalcitrant academic] (pp. 15-37). Égalité.

Hester, S., \& Eglin, P. (Eds.). (1997). Culture in action: Studies in membership categorization analysis. International Institute for Ethnomethodology and Conversation Analysis; University Press of America.

Holt, E., \& Clift, R. (Eds.). (2007). Reporting talk: Reported speech in interaction. Cambridge University Press.

Housley, W., \& Fitzgerald, R. (2002). The reconsidered model of membership categorization analysis. Qualitative Research, 2(1), 59-83.

Jayyusi, L. (1991). Values and moral judgement: Communicative praxis as a moral order. In G. Button (Ed.), Ethnomethodology and the human sciences (pp. 227-251). Cambridge University Press.

Juhila, K., \& Abrams, L. (2011). Special issue editorial: Constructing identities in social work settings. Qualitative Social Work, 10(3), 277-292.

Juhila, K., Jokinen, A., \& Saario, S. (2014). Reported speech. In C. Hall, K. Juhila, M. Matarese, \& C. van Nijnatten (Eds.), Analysing social work communication: Discourse in practice (pp. 154-172). Routledge.

Juhila, K., Raitakari, S., \& Hall, C. (Eds.). (2017). Responsibilisation at the margins of welfare. Routledge.

Knutagård, M., \& Kristiansen, A. (2013). Not by the book: The emergence and translation of housing first in Sweden. European Journal of Homelessness, 7(1), 93-115.

Mäkitalo, Å. (2014). Categorisation. In C. Hall, K. Juhila, M. Matarese, \& C. van Nijnatten (Eds.), Analysing social work communication: Discourse in practice (pp.
25-43). Routledge.

Miller, G. (1994). Towards ethnographies of institutional discourse. Journal of Contemporary Ethnography, 23(3), 280-306.

Miller, P., \& Rose, N. (2008). Governing the present: Administering economic, social and personal life. Polity Press.

Pleace, N. (2018). Bostad först-En handbok [Housing first-A handbook]. Sveriges Stadsmissioner och Égalité.

Pomerantz, A. (1986). Extreme case formulations: A way of legitimizing claims. Human Studies, 9(2), 219-229.

Psathas, G. (1999). Studying the organization in action: Membership categorization and interaction analysis. Human Studies, 22(2/4), 139-162.

Raitakari, S., \& Juhila, K. (2015). Housing first literature: Different orientations and political-practical arguments. European Journal of Homelessness, 9(1), 145-189.

Rose, N. (2000). Government and control. The British Journal of Criminology, 40(2), 321-339.

Sacks, H. (1990). On the analysability of stories by children. In J. Coulter (Ed.), Ethnomethodological sociology (pp. 254-270). Edward Elgar Publishing. (Original work published 1972)

Sacks, H. (1992). Lectures on conversation: Volumes I and II. Blackwell Publishing.

Silverman, D. (2000). Doing qualitative research: A practical handbook. SAGE.

Smith, D. (1978). 'K is mentally ill.' The anatomy of a factual account. Sociology, 12(23), 23-53.

Tsemberis, S. (2010). Housing first: The pathways model to end homelessness for people with mental illness and addiction. Hazelden.

Tsemberis, S., \& Eisenberg, R. F. (2000). Pathways to housing: Supported housing for street-dwelling homeless individuals with psychiatric disabilities. Psychiatric Services, 51(4), 487-493.

Wiggins, S., \& Potter, J. (2008). Discursive psychology. In C. Willig \& W. Hollway (Eds.), Handbook of qualitative research in psychology (pp. 72-89). SAGE.

\section{About the Authors}

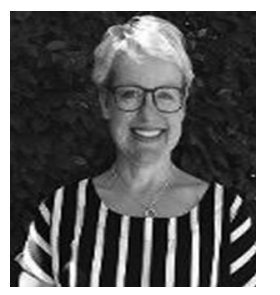

Cecilia Hansen Löfstrand is Associate Professor of sociology and Senior Lecturer in sociology at the Department of Sociology and Work Science, University of Gothenburg, Sweden. Her competence includes sociology, criminology and victimology, and she has headed and collaborated on research projects concerning the margins of welfare society and its services, victimology, public, private and voluntary policing as well as policing partnerships. She currently leads a research project on security officers' use of body-worn cameras in the private security industry.

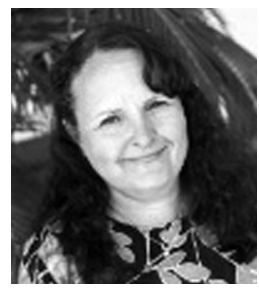

Kirsi Juhila is Professor of social work at the Faculty of Social Sciences, Tampere University, Finland. Her research interests include institutional interaction in social welfare settings and the issues of user participation, social exclusion, marginalisation and homelessness. She has methodological expertise in discourse analytic approaches. She is a member of the Margi Research Group and currently leads research projects concentrating on home visit interactions at the margins of welfare and on the processes of forced relocation of public housing residents. 